\title{
Epidemiological Characteristics and Family Relatives among Thalassemic Patients in Sulaimani City, Kurdistan Region, Iraq
}

\author{
Kamal Jalal Rashid \\ Anesthesiology Department \\ Technical College of Health \\ Sulaimani Polytechnic University \\ Sulaimani, Iraq \\ kamalashty73@yahoo.com
}

\begin{abstract}
Thalassemia is a well-known inherited hematologic disorder caused by a decrease or an absence of globin production. Patients with thalassemia suffer from chronic hemolytic anemia and its sequelae. A descriptive study was undertaken in Sulaimani Thalassemia and Congenital Blood Disease Center. The self-administered questionnaire was used to 140 patients who had thalassemia and visited to the hospital during the study periods to assess the patients' characteristics and parent's relative's relation to thalassemic patients. Data were entered into spreadsheets and analyzed in Statistical Package for Social Sciences (SPSS) version 22. Descriptive analysis was performed and frequencies and percentages were reported. Associations between categorical variables were checked using Chi-squared test. Out of 140 patients $50.0 \%$ of patients were males and $50.0 \%$ were female; the mean age was 12.8 years-old. The most frequent thalassemic patents were come from rural area $95.0 \%$. Majority of patients have major type of thalassemia $84.3 \%$. Most of the patients cannot continue to the study accounted $66.4 \%$. About number of children most of the patient's family had more than 3 children 99.3\%. Majority of patient's parents is carrier for thalassemia and accounted with 90 (65.0\%), from those patients with major thalassemia are 77 (85.6) and few cases with minor thalassemia 4 (4.4\%). These relations are statistically significant at $(p<0.05)$. Majority of patients who have major type of thalassemia were from rural area followed by urban area $113(95.8 \%)$ vs. 7 (5.0\%), these differences are statistically significant at ( $p \leq 0.01)$, from major types of thalassemic patients; 85 (94.4\%) of them were both father and mother are carrier of thalassemia. Statistically significant relation was found at $(p<0.05)$. In conclusion, thalassemia is an important cause of morbidity among thalassemic patients. In our community, thalassemia is more frequent in rural population. Therefore, it is a crucial for monitoring and examination of those who are carriers. Moreover, the lack of health education on thalassemia was the major problems related with awareness of families.
\end{abstract}

Keywords: Epidemiology, Thalassemia, Sulaimani City, Family relation, Hereditary.

\section{INTRODUCTION}

Thalassemia is an inherited blood disorder which is passed from parents to their off-spring, [1] also it's a genetic disorder lead to decreased and defective production of hemoglobin, a molecule found inside all Red Blood Cells (RBCs) that transports oxygen throughout the human body [2]. Thalassemia is a global public health problem affecting both developing and developed countries with major consequences for human health as well as social and economic development. As per the World Health Organization (WHO) database on anemia globally, anemia affects 1.62 billion people (95\%), which corresponds to $24.8 \%$ of the population. WHO also estimates that thalassemic anemia contributes to about $20 \%$ of maternal and perinatal death in developing countries [3]. Thalassemia clinically classified according to their severity into three types; thalassemia major requiring a regular blood transfusion throughout life, thalassemia intermediate characterized by anemia but not of such severity as to require regular blood transfusion, and thalassemia minor which is the symptomless carrier status [4]. There being no positive cure for thalassemia, the case-management depends solely on palliative repeated bold transfusion; thus, imposing a huge burden on the health system on the financial status of affected families. The mental agony of the affected family cannot be quantified and cannot actually be perceived by those who do no experience the trauma themselves. The most effective approach to reduce the burden on the society and reduce the disease incidence is through implementation carrier-screening program, offering genetic counseling, prenatal diagnosis and selective termination of affected fetus. In the prevention of thalassemia, social scientists and counselors have a major role to play [5].

In our community, thalassemia is more frequent in rural population. Therefore, it is a crucial for monitoring and examination of those who are carriers. Moreover, the lack of health education on thalassemia was the major problems related with awareness of families. 


\section{METHODS AND MATERIALS}

A cross-sectional study was conducted among children and adolescents, aged from 1 to 18 years-old with thalassaemia major, thalassaemia intermediate and thalassaemia minor who received regular treatment at Sulaimani Thalassemia and Congenital Blood Disease Center, Kurdistan region of Iraq, from August 2017 till January 2018. The caregivers were defined as either the father or mother of the patient. Written informed consent was obtained from all participants.

The self-administered questionnaire was used to 140 patients who had thalassemia and visited to the hospital during the study periods to assess the patients' characteristics and parent's relative's relation to thalassemic patients.

Socio demographic data and clinical parameters were obtained from the patients' medical records. These included demographics of the patients (gender, age, ethnic and educational level) and clinical information.

Statistical analysis was carried out using statistical package for social sciences (SPSS) version 22. General characteristics of the patients were presented in terms of percentage and mean. The chi-square test was used to examine the relationship between questions and each demographic/clinical parameter. A $p$ value of $\leq 0.05$ was considered statistically significant.

\section{RESULTS}

\section{Demographic characteristics of patients}

A total of 140 thalassemic patients were studied, of which 70 (50.0\%) patients were males and 50 (50.0\%) were females. The majority of patients were from rural residency 133 (95.0\%), and few patients from urban residency 7 (5.0\%). Majority of cases age were 8-18 years, followed by less or equal 7 years 81 (57.9\%). The mean age was 12.8 years (ranged from 1 month to 33 years). (Table1)

Table 1. Demographic characteristics of the patients

\begin{tabular}{|l|c|c|c|}
\hline \multicolumn{2}{|l|}{ Characteristics } & No. & $\%$ \\
\hline \multirow{2}{*}{ Gender } & Male & 70 & 50.0 \\
\cline { 2 - 4 } & Female & 70 & 50.0 \\
\hline \multirow{2}{*}{ Residency } & Rural & 133 & 95.0 \\
\cline { 2 - 4 } & Urban & 7 & 5.0 \\
\hline \multirow{3}{*}{ Age group } & $<=7$ & 36 & 25.7 \\
\cline { 2 - 4 } & $8-18$ & 81 & 57.9 \\
\cline { 2 - 4 } & $>=19$ & 23 & 16.4 \\
\hline \multicolumn{2}{|c|}{ Mean age (95\% CI) } & \multicolumn{3}{|c|}{$12.8(11.6-14.0)$} \\
\hline
\end{tabular}

\section{Types of thalassemia}

According to type of thalassemia, majority of patients have major thalassemia followed by intermediate and minor $84.3 \%, 107 \%$ and $5.0 \%$ respectively. (Figure 1)

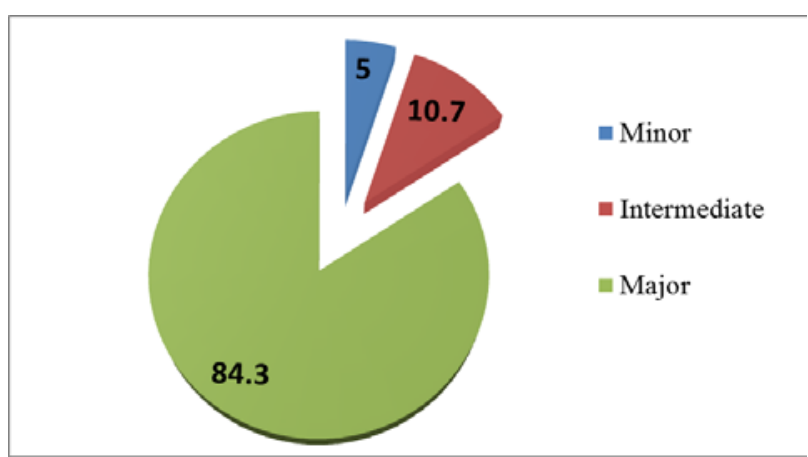

Figure 1. Distribution types of thalassemia.

\section{Family and daily living relatives to thalathimic patients}

Other parts of questioner focused on specialized questions related to the patient's family and some problems who interacting in daily living. $47.9 \%$ of patient brother and brother \& and sisters with the same diseases, while $52.1 \%$ of them without having disease among their brother and sisters. Majority of patients have no relation relatives for patient's father \& mother $51.4 \%$, but 48.6 of them have relation relatives for father \& mothers. $66.4 \%$ of patients can continue the study. Majority of cases without obstruct treatments on getting blood transfusion 75.7\% (Table 2).

Table 2. Patients problem observe living and family related to the disease

\begin{tabular}{|c|c|c|}
\hline Questions & No. & $\%$ \\
\hline \multicolumn{3}{|c|}{ Patients brother \& sister with the same disease } \\
\hline Yes & 67 & 47.9 \\
\hline No & 73 & 52.1 \\
\hline \multicolumn{3}{|c|}{ Parents relation relatives for patients } \\
\hline Yes & 68 & 48.6 \\
\hline No & 72 & 51.4 \\
\hline \multicolumn{3}{|c|}{ Any thalassemia cases in patient's fathers or mothers family } \\
\hline Yes & 50 & 35.7 \\
\hline No & 90 & 64.3 \\
\hline \multicolumn{3}{|c|}{ Patients can be continuing to study } \\
\hline Yes & 93 & 66.4 \\
\hline No & 47 & 33.6 \\
\hline \multicolumn{3}{|c|}{ Are the blood group obstructing the treatment } \\
\hline Yes & 34 & 24.3 \\
\hline No & 106 & 75.7 \\
\hline
\end{tabular}

Majority of families with 3-5 children and more than 6 children 41(50.7\%) and 68 (48.6\%) (Figure 2).

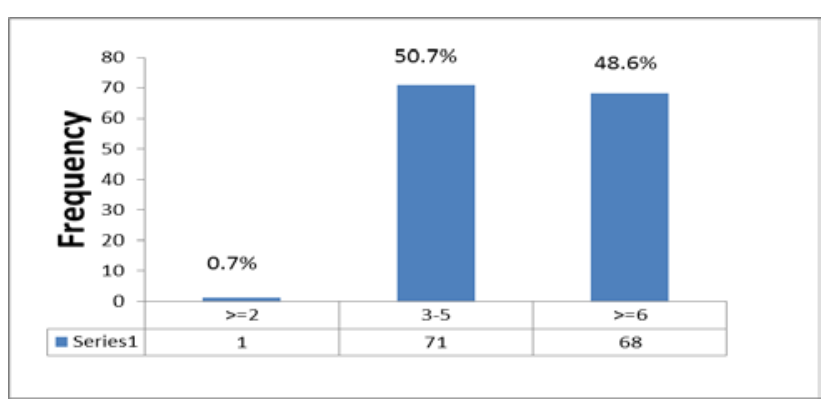

Figure 2. Frequency of the children in patient's family.

According to the history of presenting father and mothers to thalassemia, majority of patients both of 
father and mother have the disease accounted 90 (65.0\%), from those patients 77 (85.6) were with major thalassemia and few cases with minor thalassemia 4 $(4.4 \%)$ and these relations statistically significant $(\mathrm{p}=0.04)$. (Table 3)

Table 3. Distribution types of thalassemia in relation to history of fathers and mothers with the disease.

\begin{tabular}{|c|c|c|c|c|c|}
\hline \multirow{2}{*}{ 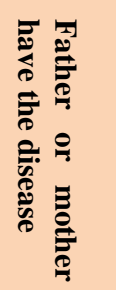 } & \multicolumn{3}{|c|}{$\begin{array}{c}\text { Type of thalassemia } \\
\text { No. }(\%)\end{array}$} & \multirow{2}{*}{ 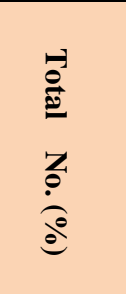 } & \multirow[b]{2}{*}{ 总 } \\
\hline & 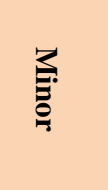 & 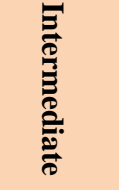 & & & \\
\hline Both & $4(4.4)$ & $9(10.0)$ & $77(85.6)$ & $90(65.0)$ & \multirow{4}{*}{0.04} \\
\hline Father & $1(5.9)$ & $2(11.8)$ & $14(83.3)$ & $17(12.0)$ & \\
\hline Mother & $2(16.7)$ & $1(8.3)$ & $9(75.0)$ & $12(8.0)$ & \\
\hline $\begin{array}{l}\text { None of } \\
\text { them }\end{array}$ & $0(0.0)$ & $3(14.3)$ & 18(85.7) & $21(15.0)$ & \\
\hline Total & $7(5.0)$ & $15(10.7)$ & $118(84.3)$ & 140 & \\
\hline
\end{tabular}

\section{Residency relation to thalassemia}

The result of residency of patients shows from 133 rural patients, 85 (94.4\%) of them were from rural area which both father and mother have the disease. While in 7 (50.0\%) patients, 5 (5.6\%) of them were from urban area. Statistically significant relation was found $\mathrm{p}=0.02$ (Table 4).

Table 4. Distribution residency of thalassemic patients in relation to history of parents with the disease

\begin{tabular}{|c|c|c|c|c|}
\hline \multirow{2}{*}{$\begin{array}{l}\text { Father or mother } \\
\text { with the disease }\end{array}$} & \multicolumn{2}{|c|}{$\begin{array}{l}\text { Residency } \\
\text { No. (\%) }\end{array}$} & \multirow{2}{*}{$\begin{array}{c}\text { Total } \\
\text { No. (\%) }\end{array}$} & \multirow{2}{*}{ 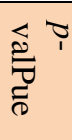 } \\
\hline & Rural & Urban & & \\
\hline Both & $85(94.4)$ & $5(5.6)$ & $90(65.0)$ & \multirow{4}{*}{0.02} \\
\hline Father & 17(100.0) & $0(0.0)$ & $17(12.0)$ & \\
\hline Mother & $12(100.0)$ & $0(0.0)$ & $12(8.0)$ & \\
\hline None of them & $19(90.5)$ & $2(9.5)$ & $21(15.0)$ & \\
\hline Total & $133(95.0)$ & $7(5.0)$ & 140 & \\
\hline
\end{tabular}

The result shows that majority of patient who have major type of thalassemia were from rural area 113 (95.8\%) and few cases from urban area 5 (4.2\%). However less frequent cases were from rural area which has minor type of thalassemia. These differences statistically significant $(\mathrm{p}=0.01)$ (Table 5).

Table 5. Distribution types of thalassemia in relation to residency of the patients.

\begin{tabular}{|l|c|c|c|c|}
\hline \multirow{2}{*}{$\begin{array}{l}\text { Types of } \\
\text { thalassemia }\end{array}$} & \multicolumn{2}{|c|}{$\begin{array}{c}\text { Residency } \\
\text { No. (\%) }\end{array}$} & \multirow{2}{*}{ Total } & \multirow{2}{*}{$p$-value } \\
\cline { 2 - 4 } & Rural & Urban & No. (\%) & \\
\hline Major & $113(95.8)$ & $5(4.2)$ & $118(84.3)$ & \multirow{2}{*}{0.01} \\
\hline Intermediate & $14(93.3)$ & $1(6.7)$ & $15(10.7)$ & \\
\hline Minor & $6(85.7)$ & $1(14.3)$ & $7(5.0)$ & \\
\hline Total & $133(95.0)$ & $7(5.0)$ & $140(100.0)$ & \\
\hline
\end{tabular}

\section{Blood transfusion}

According to the days of blood transfusions majority 72 (51.5\%) of the patients are receiving blood transfusion each less 2 weeks, while 8 (1.9\%) patients requires transfusion at longer 5 weeks. From 72 patients were receive blood transfusion less 2 weeks 68 (94.4\%) patients have major type of thalassemia, while there is no patient who receive blood transfusion with Minor type of thalassemia. Statistically significant relation was found $(p=0.03)$ (Table 6).

Table 6. Association between types of thalassemia and patient's day receiving blood transfusion.

\begin{tabular}{|c|c|c|c|c|c|}
\hline \multirow{2}{*}{ 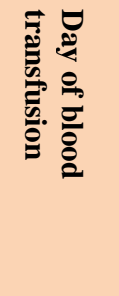 } & \multicolumn{3}{|c|}{$\begin{array}{c}\text { Type of thalassemia } \\
\text { No. }(\%)\end{array}$} & \multirow[b]{2}{*}{$\begin{array}{l}\text { Total } \\
\text { No. (\%) }\end{array}$} & \multirow[b]{2}{*}{ 冚 } \\
\hline & 当 & 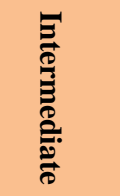 & & & \\
\hline < weeks & $0(0.0)$ & $4(5.6)$ & $68(94.4)$ & 72(51.5) & \multirow{3}{*}{0.03} \\
\hline 3-5weeks & $4(6.7)$ & $7(11.8)$ & $49(81.7)$ & $60(42.8)$ & \\
\hline$>5$ weeks & $3(37.5)$ & $4(50.5)$ & $1(12.5)$ & $8(5.7)$ & \\
\hline Total & $7(5.0)$ & $15(10.7)$ & $118(84.3)$ & 140 & \\
\hline
\end{tabular}

\section{DISCUSSION}

\section{Demographic characteristics of the patients}

\section{Gender}

For this study 140 thalassemia patients from thalassemia and congenital blood disease center in sulaimani were reunited, the study shows that gender distribution was found to be $50 \%$ female and $50 \%$ male (Table 1), because according to the current study, there is an equal chance of male and female to be effected by this thalassemia. It is nearly consistent to previous study in low-income country such as in Pakistan [2], but in Malaysian study has a little difference between male $52 \%$ and female $48 \%$ [6].

\section{Residency}

This study that shows that thalassemia in the rural area was 95\% more than urban area 5\% (Table 1), living between in rural and urban area are more difference, peoples in rural area are in our country had no information about cause and occurrence of thalassemia, prevention, diagnosis and treatments, but in the urban area they had information about it, also low educational level about risk of disease and process about presence of diseases by clinical investigations before marriage between couples who tend married to for diagnosis.

In addition, number of children with thalassemia diseases are more frequent among families living in the rural area, thus because of our culture and live style which they are more likely to get children.

Age:

In the current study, 81 patients $57.9 \%$ were aged between 8-18 years, which is nearly accordance to the 
previous study in Malaysia revealed that 75 patients aged between 11-12 years [6], however another study have a different report and showed that thalassemic patient were more frequent below 7 years of age [7].

In the present study, the thalassemia disease more appear among (8-18) years of age and decreased among the age group older than 19 years, this could be due to the quality of live and they will be dying during this age.

\section{Distribution types of thalassemia}

In our study, majority of patients have major type of thalassemia followed by intermediate and minor $84.3 \%$, $107 \%$ and $5.0 \%$ respectively, this indicated that most of the patient in the bad condition don't impotence to nutrition or may be due to their parents married regardless carrier to the diseases.

We observed that $47.9 \%$ of patient's brother and sisters with the same diseases, (Table 2), so the rate show that nearly half of patient have another brother or sister with the same disease, it means it is not important to patient's parents to have another thalassimic patient or they haven't information about the next kid.

Our study shown that majority of patients have no relation relatives for patient's father \& mother 51.4\%, but 48.6 of them have relation relatives for father \& mothers (Table 2), This finding is in agreement with the previous study which was done by Rami M. Al Haddad , this indicated that consanguinity haven't important role in the occurrence of thalassemia [8].

In our study, $33.6 \%$ of patient cannot continue to study (Table 2), it is danger proportion because of literacy has a significant role in our life which will help prevention and spread of thalassemia and it is consistence to the previous study [9].

We found that $24.3 \%$ of patients their blood groups obstruct the treatment during receiving medical care (Table 2) and it considered bad condition, because thalassimic patient have a great need to blood transfusion especially major type.

The result shows that majority of families had more than 3 children or more than 6 children (Figure 2). It is due to elevate proportion or prevalence thalassemia appearance in our population. So, arrangement and decrease child birth among those families is more important to prevent and reduce the disease level in the population.

A total of $90(65.0 \%)$ patients who their mother and father have thalassemia 77 (85.6\%) of them had major type of thalassemia, but when one of mother or father had thalassemia the proportion of major type of thalassemia will decrease among the children disease will appear. This indicate that the major type of thalassemia will transmit from parent to their off-spring when both of mother and father with the disease. This finding is agreement to the previous study [10].

In the current study, $95.8 \%$ of patients who affected to thalassemia major they are lived in countryside (Village), this indicate that those population did not yet to test before marriage of maybe they are not had information about the disease and mode of transmission. Same result was conducted in previous study [11].

\section{Blood transfusion}

Our study shows majority the patients who receive blood transfusion every 2 weeks or less, in which most of them have major type of thalassemia (Table 6). This indicate that our patients need to critical monitoring and cost, also they are high risk for other infection which are transmit to them during medical care. Same result shows in the previous study [12].

\section{CONCLUSION}

- Major type of thalassemia accounted high proportion in our community.

- Most of parent's patients (father and mother have thalassemia together).

- Families in rural area are main causes for elevating thalassemia in our community.

- The rate of major type of thalassemia present in rural population.

- Patients with thalassemia in our country need more frequent blood transfusion during weeks.

\section{REFERENCE}

[1] K. Ishfaq, THE KNOWLEDGE OF PARENTS HAVING THALASSEMIA CHILD vol. 8, 2016.

[2] Hira Tahir, Syeda Amna Shahid, and K. T. Mahmood, "Complications in Thalassaemia Patients Receiving Blood Tranfusion," J Biomed Sci and Res., vol. 3, pp. 339-346, Apr 2011.

[3] B. A. Kumar and M. Kaushik, "Blood group and anemia: Exploring a new relationship," Journal of Public Health and Epidemiology vol. 5, pp. 43-45, 2013.

[4] R. M. A. Haddad, "Molecular, biochemical and hematological investigations of $\Omega$-thalassemic children in Gaza," Faculty of Science, The Islamic University-Gaza, library.iugaza.edu.ps, 2012.

[5] Bhaswati B., saswatiN., and K. M., "A Comparative Study on Prescriptions among Parents of Thalassemic Children Attending Two Different Institutins," Indian $J$ of Community Medicine, vol. XXVIII, pp. 128-132, 2003.

[6] E. George and T. J. Ann, "Genotype-phenotype diversity of beta-thalassemia in Malaysia: treatment options and emerging therapies," Med J Malaysia, vol. 65, pp. 256-60, Dec 2010.

[7] I. A. Wahab, M. Naznin, M. Z. Nora, A. R. Suzanah, M. Zulaiho, A. R. Faszrul, et al., "Thalassaemia: a study on the perception of patients and family members," Med $J$ Malaysia, vol. 66, pp. 326-34, Oct 2011.

[8] S. Akhlaghpoor, "Chorionic villus sampling for betathalassemia: the first report of experience in Iran," Prenat Diagn, vol. 26, pp. 1131-6, Dec 2006.

[9] Nikam S. V., Dama S. B., P. S.S., and D. L. B. "LITERACY STATUS IN THALASSEMIC PATIENTS FROM SOLAPUR DISTRICT, MAHARASHTRA, INDIA: A STATISTICAL STUDY," An International Peer-reviewed J, vol. 1, pp. 22-24, Jul-Aug 2012.

[10] F. Arif, J. Fayyaz, and A. Hamid, Awareness among parents of children with thalassemia major vol. 58, 2008.

[11] F. Ishaq, H. Abid, F. Kokab, A. Akhtar, and S. Mahmood, Awareness among parents of $\beta$-Thalassemia major patients, regarding prenatal diagnosis and premarital screening vol. 22, 2012.

[12] D. Langhi Jr, E. M. A. Ubiali, J. F. C. Marques Jr, M. d. A. Verissimo, S. R. Loggetto, A. Silvinato, et al., "Guidelines on Beta-thalassemia major - regular blood transfusion therapy: Associação Brasileira de Hematologia, Hemoterapia e Terapia Celular: project guidelines: Associação Médica Brasileira - 2016," Revista Brasileira de Hematologia e Hemoterapia, vol. 38, pp. 341-345, 2016. 